\title{
Team-Based Learning in Engineering Classrooms: Feedback Form and Content Adds Value to the Learning Experience
}

\author{
Monica H. Lamm, Chemical and Biological Engineering, mhlamm@iastate.edu
}

Michael Dorneich, Industrial and Manufacturing Systems Engineering, dorneich@iastate.edu

Diane T. Rover, Electrical and Computer Engineering, drover@iastate.edu

Iowa State University, Ames IA 50011

\begin{abstract}
An instructional strategy called Team-Based Learning (TBL) has been implemented by the authors in courses that emphasize fundamental engineering concepts that are core to the discipline. TBL is an alternative to conventional classroom lecture instruction. In a TBL course, students are placed on permanent learning teams and the teams work together, during class time, to apply course concepts and solve discipline-relevant problems called application exercises. The goal of introducing TBL in these engineering courses is to enhance the quality of student learning by incentivizing student engagement with course content and fostering team skills. This is achieved by using application exercises that require student teams to apply critical thinking and decision-making abilities. Students on high performing teams routinely report that their team's success on application exercises is directly attributable to the thorough preparation by individual student team members outside of class, and that the TBL course structure helped them develop and enhance their ability to learn challenging concepts on their own. An important component of TBL course structure is the inclusion of frequent, timely, and varied types of instructional feedback to students. This paper will introduce a taxonomy for instructional feedback and place the feedback mechanisms that are inherent in the TBL course structure within this context. The form and content of instructional feedback used in TBL engineering courses will be examined. This discussion will include suggestions for achieving a balance between the dimensions of feedback to facilitate the professional development of engineering students.
\end{abstract}

\section{Introduction}

Team-Based Learning (TBL) is an evidence-based instructional strategy that has been widely used in business and medical schools, and in courses in engineering, life sciences, physical sciences, social sciences, and the humanities ${ }^{1}$. TBL has been shown to enhance the quality of student learning by fostering teamwork skills and life-long learning skills, without sacrificing the expectation that students acquire and master course concepts that are fundamental to the discipline. Courses taught using TBL require high levels of student engagement and participation, provide practice using critical thinking skills, and enhance collaboration skills. One hallmark of a TBL course design is the in-class team assignments that follow the "four S" rules $^{2}$ to ensure individual student accountability and discussion within teams and between teams. These rules are: 
1. Significant problem: teams should work on a problem that illustrates the usefulness of the course concepts in the discipline. These problems are often called application exercises by TBL instructors.

2. Same problem: teams should work on the same problem or question.

3. Specific choice: teams should be required to make a specific choice and defend that choice using course concepts.

4. Simultaneous report: teams should be required to report their answers simultaneously. This forces teams to commit to an answer and motivates them to be accountable for their decision since they will have to publicly defend it in class.

Another signature feature of a TBL course are the methods for providing instructional feedback to students that is frequent, timely, and varied. As with other active learning teaching methods, the framework for making feedback available to learners serves as a progress monitor so that students can identify their weak areas and work to improve them. It is well-known that quality feedback is an important part of the interaction between and among faculty and students. Pedagogies of engagement encourage faculty-student contact time, cooperation among students, and active learning ${ }^{3}$. A large scale study across 309 universities and over 27,000 students found that the two most powerful sources of positive influence on student's success were peer interaction and interaction with faculty ${ }^{4}$. Peer interaction strongly affected growth in problem solving skills and critical thinking skills, while interaction with faculty positively correlated with every academic outcome including grade point average and degree attainment.

While there is no question that quality instructional feedback is important to student learning and professional development, there is no clear consensus on the best way deliver this feedback to maximize its impact on learning gains and professional growth in engineering students. To begin to address this problem, in this paper we present a taxonomy of instructional feedback and demonstrate how TBL fits within this taxonomy. We then describe a TBL implementation used in a core engineering course, and evaluate its effectiveness compared to other active learning methods. We show evidence to suggest that the intentional inclusion of frequent and diverse feedback to students is having a positive impact on engineering student development. Finally, we conclude with guidance for effectively using feedback in engineering classrooms taught with TBL.

\section{A taxonomy for instructional feedback}

Feedback has many dimensions, as revealed in previous overviews and meta-analyses of instructional feedback ${ }^{5-7}$. Many different attributes and factors have been identified, and illustrate that feedback is not a uniform phenomenon, and there exists many strategies of how to provide instructional feedback ${ }^{8}$. To organize the prior work on feedback in educational contexts, we have generated a taxonomy of instructional feedback, shown in Figure 1. At the top-level, feedback is 
divided into three dimensions: Content, Form, and Use. Each of these dimensions is described below.

\section{Content}

The content of feedback can be divided into three categories: 1) course concepts, 2) learning behaviors, and 3) team skills.

\section{Course Concepts}

The core concepts of a course include the knowledge (facts and methods) of the subject, and the process to apply to those methods.

Process feedback is an assessment of whether a strategy is taking the students toward their goal, and provides students with critical information to improve performance on the tasks utilizing course concepts ${ }^{9}$. Hattie and Timperley ${ }^{5}$ define a model of feedback that has four types of feedback on: 1) the task, 2) the process, 3) the learner's ability to self-evaluate, and 4) the learner him or herself. The first two categories are defined in the course concepts part of the taxonomy, and the latter two in the learning behaviors sub-section.

\section{Learning Behaviors}

Providing feedback to students helps them gauge their learning progress and can prompt them to develop their learning behaviors ${ }^{10}$. Feedback can influence the team behavior during team $\operatorname{tasks}^{11}$.

One potential set of learning behaviors includes student's ability to reflect on their learning so far, their information gathering, and their ability to move from information gathering to idea formation. Additionally, student's ability to incorporate other perspectives, sources, approaches, and solutions into their work is supported by prompt contemplation. Students need the ability to question their assumptions, seek new information, and recognize gaps in their knowledge ${ }^{12}$. Effective feedback includes focusing on student persistence as part of their progress, strategy, and effort ${ }^{13}$.

\section{Team Skills}

The success of group depends on both the individual contributions of members as well as the member's ability to work together. On an individual level, feedback can be given on the quality and consistency of their contribution towards team goals. The types of feedback on the team level can vary. One model of teamwork describes "the big five" components of teamwork that lead to team success: team leadership, mutual performance monitoring, backup behavior, adaptability, and team orientation ${ }^{14}$. While we draw on the Salas et al. model in our taxonomy, other models of teamwork exist. For instance, Smith et al. ${ }^{3}$ list skills that lead to the success of cooperative efforts as leadership, decision making, trust building, communication, and conflict management. 
Effective team leadership can improve the effectiveness of a team by facilitating problem solving, coordinating, and motivating the team ${ }^{14,15}$. Although traditionally difficult to measure, mutual performance monitoring includes the team members' ability to keep track of each other's work and ensuring that the work is getting done and that the proceses are being followed. Backup behavior is the ability of teammates to recognize problems in workload distribution and mitigate $^{16}$. For instance, one team member can provide feedback and coaching to another underperforming member, or redistribute tasks ${ }^{17}$. The adaptability of a team allows it to recognize problems with the plan and adjust actions to compensate ${ }^{18}$. Finally, team orientation focuses on the motivation and attitudes of team members, which when positive can, facilitate performance and influence team cooperation ${ }^{11,19}$.

\section{Form of Feedback}

\section{Modality}

Feedback can be given in a variety of modalities: written, verbal, and even tactile. Often the appropriate modality is determined by choices in other aspects of the feedback. Summative feedback provided on homework is often written, while immediate feedback during an on-class exercise is verbal. For instance, verbal feedback was shown to be effective when giving feedback on goal setting during football practice. ${ }^{20}$

\section{Timing}

Feedback can be immediate or delayed. Mory ${ }^{7}$ provides an overview of the previous literature comparing the utility of immediate or delayed feedback. Sometime the nature of the task determines when feedback can be given. Feedback given at the wrong time can be detrimental to the outcomes desired ${ }^{21}$. Immediate feedback has been shown to prevent the formation of incorrect associations, ${ }^{22}$ and does not withhold information that the learner can use ${ }^{23}$. One of the seven principles for good practice in undergraduate education is "give prompt feedback" 24 . On the other hand, delayed feedback has been shown in some context to be more beneficial to student retention and learning that immediate feedback ${ }^{25,26}$. Additionally, it may be important to let the student complete the task uninterrupted in order to enable him or her to learn how to identify their own errors ${ }^{27}$. However, for team delayed feedback may be detrimental to group motivation $^{28}$.

\section{Formality}

The manner in which feedback is given can greatly influence its helpfulness ${ }^{21}$. Explicit feedback is where both the source and the recipient know that intentional feedback is being delivered. Implicit feedback is where the information provided by the source may not be recognized as 'feedback' by the recipient. 


\section{Type}

Feedback usually serves one of two goals: 1) positive feedback to encouraging students to continue that is appropriate and effective, or 2) negative feedback to correct or eliminate behaviors or misconceptions in inappropriate or ineffective ${ }^{12,21}$.

\section{Source and Destination}

Feedback can be directed at an individual, group, or class. The source and destination of feedback can be combined to characterize various well known feedback mechanisms, such as class feedback from the instructor, peer-to-peer feedback within a group, or even class feedback to the instructor. Often feedback mechanism creates multiple types of feedback; for instance, the plus/delta evaluation creates feedback from s the class to the instructors, as well as reflective feedback between students. Research in learning from pre-school to higher education has shown that one of the most powerful forms of feedback is from the student to the teach, through which the teach is able to assess student knowledge, understanding, and misconceptions ${ }^{12}$.

In engineering education, feedback has primarily been studied in the context of feedback to and within student design teams. In one study ${ }^{9}$, instructors implemented a peer assessment system based on six semesters of student-generated criteria for communicating helpful process and behavioral feedback. These authors found that after implementation of this feedback system, negative team outcomes (personality conflicts, social loafing) were eliminated and the quality of the design team deliverables improved. In another study ${ }^{29}$, the use of agile project management for a two-semester senior design project is documented by profiling the experience of the student design team, client, and faculty mentor. The agile project management framework required the student team to work in two-week "sprint" iterations, where each sprint contained a deliverable, followed by a progress meeting with the client and mentor. The use of frequent feedback during sprints enabled the student team to develop a high quality product and better preparation for engineering practice.

\section{Uses of Feedback}

Feedback can be used for many purposes. In the engineering evaluation literature, evaluations and assessment are often divided into "formative" and "summative",

\section{Formative}

Formative evaluations are often informal evaluation used to gather feedback while a task is still underway or while a design is stull forming. A summative evaluation looks to establish (or summarize) some claims over a baseline. In an educational setting, formative feedback can be feedback given informally during task execution, often with the goal of improving the process or solution as it is being developed. Examples might include instructors providing verbal feedback during a group activity in class. 


\section{Summative}

Summative feedback might be formal assessment like exam grades that assess level of mastery of the content or skill, or written feedback on a term paper.

\section{Implementation of Team-Based Learning in an engineering course}

This section describes the course organization for a TBL implementation of a material and energy balances course taught to second-year chemical engineering students. To evaluate the effectiveness of the TBL implementation, assessment data for this course is compared to data from a section of the same course taught using other active learning methods.

\section{Course organization for the TBL implementation}

On the first day of class, the students were assigned to learning teams of 6 to 7 students. The teams were assigned by the instructor, according to the geographical location where the students attended high school (in-state, out-of-state, international). The students were divided into these three categories and then distributed among teams to ensure that each team had the same distribution of geographical categories represented. The team assignments remained permanent for the duration of the course. All exercises and problems that were assigned to the student teams were completed during the class session. There was no expectation that the students would meet with their team outside of class. Outside of class, individual students prepared for each classroom session by completing a reading assignment, one or more assigned example problems, and one homework problem. Students submitted the homework problem to receive individual feedback on their work and a grade for the assignment. During class, the student learning teams solved application exercises and received immediate feedback on their answers from the instructor and from other teams. The daily team scores on the application exercises were counted in the determination the course grades of individual students. Three in-class exams were given at weeks 5, 9, and 13. A final exam was given at the end of the term.

The instructional methods and materials used in the TBL section included:

- Reading assignments. The students were given one reading guide per classroom instruction session. Each reading guide was made available five to ten days before the class meeting. The reading guides contained a list of learning objectives, a detailed reading assignment, example problems, and one homework problem.

- Homework problems. The students were given one homework assignment per class meeting and it was completed by individual students outside of class and submitted for a grade.

- Readiness assessment quizzes. Prior to the start of a new module, the students completed a reading assignment designed to review the essential prerequisite knowledge needed to be ready to learn the new concepts introduced in the module. On the first day of the module, the students took a short readiness assessment quiz, first individually, then with 
their team. The individual and team quizzes were scored and contributed to the final course grade.

- Classroom instruction. A typical day of classroom instruction included 10 minutes of lecture from the instructor and 40 minutes of team problem-solving activities performed by the students. The team answers were scored and contributed to the final course grade.

\section{Course organization for the IAL section - a control}

The effectiveness of the TBL instructional strategy was evaluated by comparison to a section of the course taught using informal active learning (IAL) instruction methods. The use of the IAL section as the control implementation is justified for the following reasons. The same instructor taught the IAL and TBL sections. The IAL section was taught two years prior to the TBL section. At the time the IAL section was taught, the instructor was teaching the course with IAL for the fourth time, with a highly developed set of lesson plans, and hence, this offering represents the instructor's best implementation of the course taught with IAL methods.

The common components between the TBL and IAL sections were as follows. Both sections were taught to second-year chemical engineering students by the same instructor, and used the same textbook ${ }^{31}$. Each section met for three 50-minute sessions of classroom instruction per week for 15 weeks. Three in-class exams were given at weeks 5, 9, and 13. A final exam was given at the end of the term. Students were provided with a study guide for each exam and these study guides changed very little between course offerings. The content covered on each exam was the same but due to concerns about student access to course material from prior years, identical exams were not used.

The instructional methods and materials used in the IAL section included:

- Reading assignments. In IAL, the students were given a list of reading assignments at the beginning of the semester and encouraged to read the designated sections of the textbook ahead of class.

- Homework problems. The students were given two homework assignments per week. The homework set due on Mondays was an assignment that was completed by individual students outside of class. The homework set due on Fridays was a more challenging assignment that was completed by groups of 3 to 4 students outside of class. Homework teams were assigned by the instructor by taking into account grades in prerequisite courses and compatible study schedules. The team assignments were permanent for the duration of the semester.

- Classroom instruction. A typical day of classroom instruction included 30 minutes of lecture by the instructor and 20 minutes of active learning activities (turn to a partner, think-pair-share, get into a group of 3 (or 4) and decide what the next step in this solution should be) performed by the students. No more than five minutes was allotted for any single active learning activity and the active learning activities were interspersed 
throughout the instructor's lecture. ${ }^{32}$ To keep students on task, they were put on notice that the instructor would call on them to report their answer at the end of an activity.

\section{Methods for collecting and analyzing the assessment data}

The TBL and IAL sections were compared using student performance on course exams, and student responses to formative and summative course surveys. These data were collected for a TBL section and an IAL section of a material and energy balances course.

The TBL section was taught in 2012 and the IAL section was taught in 2010. Profiles of the students enrolled in the IAL and TBL sections are shown in Table 1 . There was a $43 \%$ increase in enrollment between the IAL section offered in 2010 and the TBL section offered in 2012. This enrollment increase follows the rising enrollment trend in the instructor's department. Students had no prior knowledge that the course would be taught using TBL prior to enrolling. The gender distribution between the two sections was nearly the same. The average composite ACT score between the two sections differed by one point. The distribution of ACT scores is shown in Figure 2.

The exam scores from students in the TBL and IAL sections were compared as follows. There were three mid-semester exams and a final exam given to each section of the course. Due to concerns about student access to course material from prior years, identical exams were not used. For both sections, the three mid-semester exams were given at the end of weeks 5, 9, and 13 . The content covered by an exam at a particular point in the semester was the same and the exam questions, while different, assessed the same course concepts. In the instructor's experience, there is unintended variability in the difficulty of the exam questions throughout a given semester. For example, in one year, Exam 1 may have had the most difficult question of the semester, while in another year, the most difficult question may have appeared on Exam 3. This limits the usefulness of a direct comparison of the student exam scores on a given exam between two course offerings. To reduce the effect that variations in the difficulty of exam questions might have, an average exam score for each student was computed. This average exam score was compared to the criterion-referenced grading scale shown in Table 2 and a letter grade (A, B, C, D, or F) was assigned to the average exam score earned by each student.

Student responses to the course were collected by voluntary formative and summative course evaluation surveys. The formative course evaluation survey questions were based on the Plus/Delta classroom assessment method $^{33}$. The formative survey was administered at mid-term and asked these four questions: i) What is helping you to learn in this course?, ii) What changes in this course are needed to improve learning?, iii) What are you doing to learn in this course?, iv) What do you need to do to improve your learning in this course?. The responses from the IAL section were collected on paper and the responses from the TBL section were collected with an online form. No response rate was recorded for the IAL section. Sixty-three (63) students 
completed the formative survey in the TBL section (response rate of 91\%). For both the IAL and TBL sections, the instructor reviewed the student responses and grouped them by theme.

The summative course evaluation was administered by paper for the IAL section and online for the TBL section. The paper and online surveys asked the same questions and the response choices were based on a five-point Likert scale. Space was allocated at the end of the survey for additional, open-ended comments. The instructor grouped these responses and grouped them by theme. Thirty-two students responded in the IAL section (response rate of $73 \%$ ) and 33 students responded in the TBL section (response rate of 52\%).

\section{Results}

Impact of TBL instruction on problem-solving skills

Problem-solving ability was measured by four exams given over the duration of the semester. For each student, an average exam score was calculated and converted to a letter grade using the criterion-referenced grading scale shown in Table 2. Figure 3 shows the percentage distribution of students who earned letter grades of A, B, C, D, or F. There is no significant difference in average student exam scores between the IAL and TBL sections.

This finding may be due to the fact that in this study, both the intervention (TBL) and the control (IAL) used evidence-based active learning pedagogy. Based on an earlier study ${ }^{3}$ using active learning techniques that closely align with the IAL control, it is expected that students in either the IAL or the TBL section would score higher than students in a section where instruction was delivered by conventional classroom lecture. It is promising that a first-time implementation of TBL is at least as effective as the best implementation of IAL, for a given instructor. Future studies could be devoted to improved research designs that would yield evidence to specifically identify the differences in problem-solving ability between students in TBL and IAL courses on the same topic.

\section{Impact of TBL on perceived attainment of learning outcomes}

Students self-reported their attainment of course learning outcomes on the summative course evaluation survey. Figure 4 shows the percentage distribution of student responses indicating their perception of their mastery of three course learning outcomes.

In all three learning outcome categories surveyed, the percentage of students who responded "agree" or "strongly agree" was higher for the IAL section than for the TBL section. The total percentage of students who chose "agree" or "strongly agree" is as follows: a) "You understand and are able to develop and use material and energy balance equations" (88\% IAL; 78\% TBL); b) "You can create process diagrams for simple and moderately complex chemical systems" (97\% IAL; 72\% TBL); c) "You can solve material and energy balance problems using various 
computational tools" (78\% IAL; 66\% TBL). This finding is unexpected, given that the average exam scores earned by the students in both sections had nearly the same distribution.

Why would the students in the TBL section not report the same level of achievement on course learning outcomes? The explanation may be in the way the course content was delivered. Research studies have shown that students report inflated judgments of learning when the learning activity involves copying information rather than constructing information. ${ }^{35,36}$ In the IAL section, the students spent approximately 90 minutes per week copying notes as the instructor solved examples on the board. In this setting, it is more likely that an IAL student feels more confident about his/her abilities because of the perceived ease of processing the content, sometimes called the "familiarity pitfall". ${ }^{37}$ Conversely, TBL students spent much less time copying notes from the instructor $(<30$ minutes per week) and more time in class on learning activities that required them to apply course concepts and construct knowledge for themselves. Thus, the TBL students perceived ease of processing was likely lower, thereby reducing their self-reported rating of achievement on course learning outcomes.

\section{Impact of TBL on professional development}

Student perceptions about their professional development were measured by the summative course evaluation survey. Figure 5 shows the percentage distribution of student responses indicating their perception of how the course offered opportunities for professional growth in three categories.

In the three learning outcome categories surveyed, the percentage of students who responded "agree" or "strongly agree" was nearly the same for the IAL and TBL sections. The total percentage of students who chose "agree" or "strongly agree" is as follows: a) "This course provided you with an opportunity to develop skills in engineering design" (69\% IAL; 66\% TBL); b) "This course provided you with an opportunity to work effectively as a member of a team" (91\% IAL; 88\% TBL); c) "This course provided you with an opportunity to demonstrate knowledge through presentation of technical information" (66\% IAL; 69\% TBL).

Open-ended responses were collected from the IAL and TBL sections using the summative course evaluation survey, and from the TBL section using a plus-delta ${ }^{33}$ formative survey at midterm. The following themes were identified from the qualitative assessment.

The TBL course helped students develop and improve their self-study skills. Students could observe their peers at every class meeting and this helped individuals discover what kinds of self-study strategies were most effective for them. The structure of the TBL course reinforced the strong self-study skills of the students who had them. Other students noted that their selfstudy skills improved during the semester. 
The TBL course promoted a shift in thinking. Several students commented that they changed the way they approach problems because of their regular interactions with their learning team.

The TBL course format provided the students with opportunities to lead and organize a group of peers. The students recognized the value of this early experience with team-building and its importance to their future success at the university and in the workplace. The importance of collegiality to team function was noted.

The TBL feedback framework promotes the development of professional skills and workplace competencies

As noted earlier, TBL provides a rich experiential environment, in which students learn not only from the methods and materials listed above, but from the skills and behaviors cultivated through the TBL experience itself. Professional skills for engineering students have been identified in several ways in the ABET Engineering Criteria, including Criterion 3, Student Outcomes; Criterion 5, Curriculum; and Program Criteria for specific programs. ${ }^{38}$ For example, ABET engineering student outcomes (d), (f), (g), (h), (i), and (j), listed below, have been referred to as professional skills. ${ }^{39}$

(a) an ability to apply knowledge of mathematics, science, and engineering

(b) an ability to design and conduct experiments, as well as to analyze and interpret data

(c) an ability to design a system, component, or process to meet desired needs within realistic constraints such as economic, environmental, social, political, ethical, health and safety, manufacturability, and sustainability

(d) an ability to function on multidisciplinary teams

(e) an ability to identify, formulate, and solve engineering problems

(f) an understanding of professional and ethical responsibility

(g) an ability to communicate effectively

(h) the broad education necessary to understand the impact of engineering solutions in a global, economic, environmental, and societal context

(i) a recognition of the need for, and an ability to engage in lifelong learning

(j) a knowledge of contemporary issues

(k) an ability to use the techniques, skills, and modern engineering tools necessary for engineering practice

A recent national study concluded that professional topics are typically emphasized in first-year design and capstone courses rather than integrated throughout the curriculum. ${ }^{40}$ However, students may develop professional skills through the behaviors they practice in the learning process, in addition to any topical coverage. Thus instructional strategies used in the classroom, such as TBL, provide an opportunity for professional skills development in core engineering courses. 
At Iowa State, the engineering college has adopted a set of workplace competencies based on the needs of engineering employers. ${ }^{41}$ In the college's framework, student outcomes are multidimensional and represent some collection of workplace competencies necessary for the practice of engineering at the professional level. Fifteen competencies are measured within this framework: Analysis and Judgment, Communication, Continuous Learning, Cultural Adaptability, Customer Focus, Engineering Knowledge, General Knowledge, Initiative, Innovation, Integrity, Planning, Professional Impact, Quality Orientation, Safety Awareness, and Teamwork. Each competency is uniquely defined with a set of observable and measurable key actions that a student may take that demonstrates development of that competency. Many of these competencies are evident in the TBL method. For example, the assessment results presented for the material and energy balances course showed that TBL helped students develop and improve their self-study skills. This corresponds to the continuous learning competency, which also aligns with ABET outcome (i) on lifelong learning; it is defined as follows: Actively identifying new areas for learning; regularly creating and taking advantage of learning opportunities; using newly gained knowledge and skill on the job and learning through application. Several representative workplace activities associated with the competency are:

- Designing experiments or products that require engineers to learn new subject areas.

- Engaging in discussions on professional responsibility.

- Using feedback from customers to learn new material that will improve a product.

- Reading/viewing new material and attending seminars.

- Learning local, state, and federal laws to understand impact on engineering practices.

- Learning new tools to design a product or solve a problem.

Thus TBL gives students early practice with professional competencies that employers expect to see in the workplace. These opportunities are highlighted in Table 2, which shows the learning activities offered in the TBL implementation of the material and energy balances course and classifies them according to the content and form of the feedback.

\section{Conclusions and recommendations for using TBL in engineering courses}

TBL is an effective instructional strategy for teaching problem-solving skills in engineering. In an introductory engineering problem-solving course, students in the TBL section performed as well as students in the IAL section that was taught with an informal active learning approach. Given that the students achievement on course learning outcomes, as measured by exam scores, was maintained while students developed early team-building skills and improved self-study skills suggests that teaching with the TBL instructional strategy is an effective way to integrate professional competencies into engineering courses. Further study is needed to directly examine the feedback mechanisms in TBL and their impact on the development of learning behaviors and workplace skills. 
Based on our collective experience with developing TBL courses in engineering, we offer the following suggestions to engineering educators who wish to adopt TBL. It is likely that most engineering students have never taken a TBL course before and therefore, it is important to orient students to TBL procedures and provide ample explanation for why you are choosing to use TBL. We suggest spending the first 1 or 2 class periods on TBL orientation activities, keeping the stakes low, to acclimate students to the course mechanics. The team-based learning collaborative $^{42}$ has many ideas for application exercises aimed at course goals that can be adapted to suit any course. Be intentional about incorporating both conceptual and behavioral feedback into the learning activities offered in the course, to promote a broad range of student development. Be aware that because much of the feedback that takes place occurs during verbal exchanges during classroom time, while student teams are solving application exercises, that some students may not recognize that the feedback they are receiving from their instructor and their peers is pertinent to their learning. It is important to be explicit with students about the types of feedback they will be receiving and how they can use that information. Sharing a classification of course activities, like shown in Table 2, may especially help those students who have a difficult time accepting that an instructor can be offering rich learning experiences without lecturing. Helping students recognize when feedback is being offered, will help reinforce the notion that the ability to accept feedback as objective comments, rather than criticism, is a valued professional skill.

\section{Bibliography}

1. L. K. Michaelsen, A. B. Knight, and L. D. Fink (Eds), Team-Based Learning: A Transformative Use of Small Groups in College Teaching, Stylus Publishing, Sterling (VA) (2004).

2. L. K. Michaelsen and M. Sweet, "The essential elements of team-based learning," in Team-Based Learning: Small Group Learning's Next Big Step, New Directions for Teaching and Learning, 116, pp 7 - 27 (2008).

3. Smith, Sheppard, Johnson, and Johnson, "Pedagogies of Engagement: Classroom-Based Practices" Journal of Engineering Education, 94, 87-101 (2005).

4. Astin, A. What matters in college: Four critical years revisited. San Francisco, Jossey-Bass (1993).

5. Hattie, J., \& Timperley, H. (2007). The power of feedback. Review of educational research, 77(1), 81-112.

6. Kluger, A. N., \& DeNisi, A. (1996). The effects of feedback interventions on performance: a historical review, a meta-analysis, and a preliminary feedback intervention theory. Psychological bulletin, 119(2), 254.

7. Mory, E. H. (2004). Feedback research revisited. Handbook of research on educational communications and technology, 2, 745-783.

8. Lawton, D., Vye, N., Bransford, J., Sanders, E., Richey, M., French, D., \& Stephens, R. (2012). Online learning based on essential concepts and formative assessment. Journal of Engineering Education, 101(2), 244-287.

9. Lane, D., \& Trader, R. J. (2007). Engineering feedback: A student-developed approach to the assessment of peer evaluation in civil engineering. Chicago: National Communication Association.

10. J. Handelsman, S. Miller, and C. Pfund, (2007). Scientific Teaching, W. H. Freeman, New York. 
11. Driskell, J. E., \& Salas, E. (1992). Collective Behavior and Team Performance. Human Factors: The Journal of the Human Factors and Ergonomics Society, 34(3), 277-288. doi:10.1177/001872089203400303

12. TILT (2011). High Fidelity Feedback Moves Learning Forward. Techniques in Learning \& Teaching. Available at: http://uminntilt.wordpress.com/2011/09/20/high-fidelity-feedback-moves-learning-forward/

13. NCWIT (2014). NCWIT Tips: 8 Ways to Give Students More Effective Feedback Using a Growth Mindset. National Center for Wonemn and Infromation Technology. Availabel online at: http://www.ncwit.org/resources/ncwit-tips-8-ways-give-students-more-effective-feedback-using-growthmindset/ncwit-tips-8

14. Salas, E., Sims, D. E., \& Burke, C. S. (2005). Is there a "Big Five" in Teamwork? Small Group Research, 36(5), 555-599. doi:10.1177/1046496405277134

15. Zaccaro, S. J., Rittman, A. L., \& Marks, M. a. (2001). Team Leadership. The Leadership Quarterly, 12(4), 451-483. doi:10.1016/S1048-9843(01)00093-5.

16. Porter, C. O. L. H., Hollenbeck, J. R., Ilgen, D. R., Ellis, A. P. J., West, B. J., \& Moon, H. (2003). Backing up behaviors in teams: the role of personality and legitimacy of need. The Journal of Applied Psychology, 88(3), 391-403. Retrieved from http://www.ncbi.nlm.nih.gov/pubmed/12814289

17. Marks, M. A., Mathieu, J. E., \& Zaccaro, S. J. (2001). A Temporally Based Framework and Taxonomy of Team Processes. Academy of Management Review, 26(3), 356-376.

18. Priest, Burke, Munium, and Salas, 2002

19. Eby, L. T., \& Dobbins, G. H. (1997). Collectivistic orientation in teams : an individual and group-level analysis. Journal of Organizational Behavior, 18, 275-295.

20. Smith, S. L., \& Ward, P. (2006). Behavioral Interventions to Improve Performance in Collegiate Football. Journal of Applied Behavior Analysis, 39(3), 385-391. doi:10.1901/jaba.2006.5-06

21. Michaelsen, L. K., \& Schultheiss, E. E. (1988). Making feedback helpful. Organizational Behavior Teaching Review, 13(1), 109-113.

22. Epstein, M. L., Lazarus, A. D., Calvano, T. B., Matthews, K. A., Hendel, R. A., Epstein, B. B., \& Brosvic, G. M. (2010). Immediate feedback assessment technique promotes learning and corrects inaccurate first responses. The Psychological Record, 52(2), 5.

23. Dempsey, J. V., Driscoll, M. P., \& Swindell, L. K. (1993). Text-based feedback. In J. V. Dempsey and G. C. Sales (Eds.), Interactive instruction and feedback (pp. 21-54). Englewood Cliffs, NJ: Educational Technology Publications.

24. Chickering, A. W., \& Gamson, Z. F. (1987). Seven principles for good practice in undergraduate education. AAHE bulletin, $3,7$.

25. Butler, A. C., Karpicke, J. D., \& Roediger, H. L. (2007). The effect of type and timing of feedback on learning from multiple-choice tests. Journal of Experimental Psychology. Applied, 13(4), 273-81. doi:10.1037/1076-898X.13.4.273

26. Walsh, C. M., Ling, S. C., Wang, C. S., \& Carnahan, H. (2009). Concurrent versus terminal feedback: it may be better to wait. Academic Medicine : Journal of the Association of American Medical Colleges, 84(10), S547. doi:10.1097/ACM.0b013e3181b38daf

27. Corbett, A. T., \& Anderson, J. R. (2001). Locus of Feedback Control in Computer-Based Tutoring: Impact on Learning Rate, Achievement and Attitudes. In Proceedings of the SIGCHI conference on Human factors in computing systems (pp. 245-252).

28. Gabelica, C., Bossche, P. Van Den, Segers, M., \& Gijselaers, W. (2012). Feedback, a powerful lever in teams: A review. Educational Research Review, 7(2), 123-144. doi:10.1016/j.edurev.2011.11.003

29. Rover, D., C. Ullerich, R. Scheel, J. Wegter, and C. Whipple, “Advantages of Agile Methodologies for Software and Product Development in a Capstone Design Project," to appear, Proc. of IEEE/ASEE 2014 Frontiers in Education Conference, Madrid, Spain, October 22-25, 2014.

30. Twidale, M., Randall, D., \& Bentley, R. (1994, October). Situated evaluation for cooperative systems. In Proceedings of the 1994 ACM conference on Computer supported cooperative work (pp. 441-452). ACM.

31. Felder, R. M. and Rousseau, R. W., Elementary Principles of Chemical Processes, 3rd edition, Wiley, Hoboken (NJ) (2005).

32. Bullard, L. G. and Felder, R. M., "A student-centered approach to teaching Material and Energy Balances: 2. Course delivery and assessment", Chemical Engineering Education, 41, 167-176 (2007).

33. Helminski, L. and Koberna, S. (1995). Total quality in instruction: A systems approach. In H. V. Roberts (Ed.), Academic initiatives in total quality for higher education (pp 309-362). Milwaukee, WI: ASQC Quality Press.

34. R. M. Felder, G. N. Felder, and E. J. Deitz, "A longitudinal study of engineering student performance and retention. V. Comparisons with traditionally-taught students," Journal of Engineering Education, 1998. 
35. Agarwal, P. K., Karpicke, J. D., Kang, S. H. K., Roediger, H. L. III., \& McDermott, K. B. (2008). Examining the testing effect with open- and closed-book tests. Applied Cognitive Psychology, 22, 861-876.

36. Carpenter, S. K., \& Olson, K. M. (2012). Are pictures good for learning new vocabulary in a foreign language? Only if you think they are not. Journal of Experimental Psychology: Learning, Memory, \& Cognition, 38, 92101.

37. R. Wright (2014). National Academies Northstar Summer Institute on Scientific Teaching, University of Minnesota.

38. 2014-2015 Criteria for Accrediting Engineering Programs, ABET Engineering Accreditation Commission, ABET, 2013.

39. Shuman, Larry, Mary Besterfield-Sacre, and Jack McGourty, "The ABET professional skills - can they be taught? can they be assessed?" Journal of Engineering Education, January 2005.

40. McHale, I.M., L.R. Lattuca, P.T. Terenzini, and A.C. Yin, "Work in progress- all aboard the engineer of 2020 ? Programs chairs' and faculty members' reports of curricular emphases," Proc. 2010 ASEE/IEEE Frontiers in Education Conference, 2010.

41. Brumm, Tom, Larry Hanneman, and Steven Mickelson, "Assessing and developing program outcomes through workplace competencies," International Journal of Engineering Education, 22(1), 2006.

42. The Team-Based Learning Collaborative, http://www.teambasedlearning.org/. 
Table 1. Student profiles for IAL and TBL sections of a material and energy balance course.

\begin{tabular}{|l|l|l|}
\hline & IAL (2010) & TBL (2012) \\
\hline$N$ (number enrolled) & 44 & 63 \\
\hline Male & $73 \%$ & $71 \%$ \\
\hline Female & $27 \%$ & $29 \%$ \\
\hline Average composite ACT score & 28 & 29 \\
\hline
\end{tabular}


Table 2. Classification of learning activities offered in the TBL implementation of a material and energy balances course.

\begin{tabular}{|c|c|c|c|c|c|c|}
\hline Activity & $\begin{array}{l}\text { Time } \\
\text { spent on } \\
\text { activity } \\
\text { (min) }\end{array}$ & Who & Where & $\begin{array}{l}\text { Feedback } \\
\text { form }\end{array}$ & $\begin{array}{l}\text { Feedback } \\
\text { content }\end{array}$ & $\begin{array}{l}\text { Number } \\
\text { of times } \\
\text { per } \\
\text { semester }\end{array}$ \\
\hline $\begin{array}{l}\text { Pre-class } \\
\text { reading } \\
\text { assignment }\end{array}$ & 60 & Individual & $\begin{array}{l}\text { Out of } \\
\text { class }\end{array}$ & $\begin{array}{l}\text { Concept } \\
\text { questions } \\
\text { in textbook } \\
\text { (answers } \\
\text { provided in } \\
\text { back) }\end{array}$ & $\begin{array}{l}\text { Check } \\
\text { conceptual } \\
\text { understanding } \\
\text { of assigned } \\
\text { reading }\end{array}$ & 40 \\
\hline $\begin{array}{l}\text { Solving the } \\
\text { pre-class } \\
\text { problem }\end{array}$ & 120 & Individual & $\begin{array}{l}\text { Out of } \\
\text { class }\end{array}$ & $\begin{array}{l}\text { Score on } \\
\text { grading } \\
\text { rubric }\end{array}$ & $\begin{array}{l}\text { Guidance on } \\
\text { problem- } \\
\text { solving } \\
\text { approach and } \\
\text { mechanics }\end{array}$ & 34 \\
\hline $\begin{array}{l}\text { Note-taking } \\
\text { during lectures } \\
\text { presented to } \\
\text { class }\end{array}$ & 10 & Individual & In class & None & None & 40 \\
\hline $\begin{array}{l}\text { Individual } \\
\text { readiness } \\
\text { assessment } \\
\text { (quiz) }\end{array}$ & 20 & Individual & In class & Score & $\begin{array}{l}\text { Check } \\
\text { conceptual } \\
\text { understanding } \\
\text { of current topic }\end{array}$ & 6 \\
\hline $\begin{array}{l}\text { Team } \\
\text { readiness } \\
\text { assessment } \\
\text { (quiz) }\end{array}$ & 20 & Team & In class & Score & $\begin{array}{l}\text { Check } \\
\text { conceptual } \\
\text { understanding } \\
\text { of current topic }\end{array}$ & 6 \\
\hline $\begin{array}{l}\text { Writing } \\
\text { appeals for } \\
\text { missed } \\
\text { questions on } \\
\text { readiness } \\
\text { assessment } \\
\end{array}$ & 10 & Team & In class & $\begin{array}{l}\text { Written } \\
\text { response } \\
\text { from } \\
\text { instructor }\end{array}$ & $\begin{array}{l}\text { Guidance on the } \\
\text { use of evidence } \\
\text { to construct an } \\
\text { argument }\end{array}$ & 6 \\
\hline $\begin{array}{l}\text { Solving } \\
\text { application } \\
\text { exercises with } \\
\text { team }\end{array}$ & 40 & Team & In class & $\begin{array}{l}\text { Verbal } \\
\text { responses } \\
\text { from } \\
\text { instructor } \\
\text { and from } \\
\text { peers }\end{array}$ & $\begin{array}{l}\text { Guidance on } \\
\text { application of } \\
\text { course } \\
\text { concepts; } \\
\text { comparison of } \\
\text { self-study to } \\
\text { group norm }\end{array}$ & 34 \\
\hline $\begin{array}{l}\text { Written } \\
\text { comments } \\
\text { from peers }\end{array}$ & 30 & Individual & $\begin{array}{l}\text { Out of } \\
\text { class }\end{array}$ & $\begin{array}{l}\text { Written } \\
\text { responses } \\
\text { from peers }\end{array}$ & $\begin{array}{l}\text { Comparison of } \\
\text { team skills to } \\
\text { group norm }\end{array}$ & 2 \\
\hline $\begin{array}{l}\text { Self-reflection } \\
\text { at mid-term }\end{array}$ & 30 & Individual & $\begin{array}{l}\text { Out of } \\
\text { class }\end{array}$ & $\begin{array}{l}\text { Written } \\
\text { summary } \\
\text { from } \\
\text { instructor }\end{array}$ & $\begin{array}{l}\text { Comparison of } \\
\text { study habits to } \\
\text { class norm }\end{array}$ & 1 \\
\hline
\end{tabular}




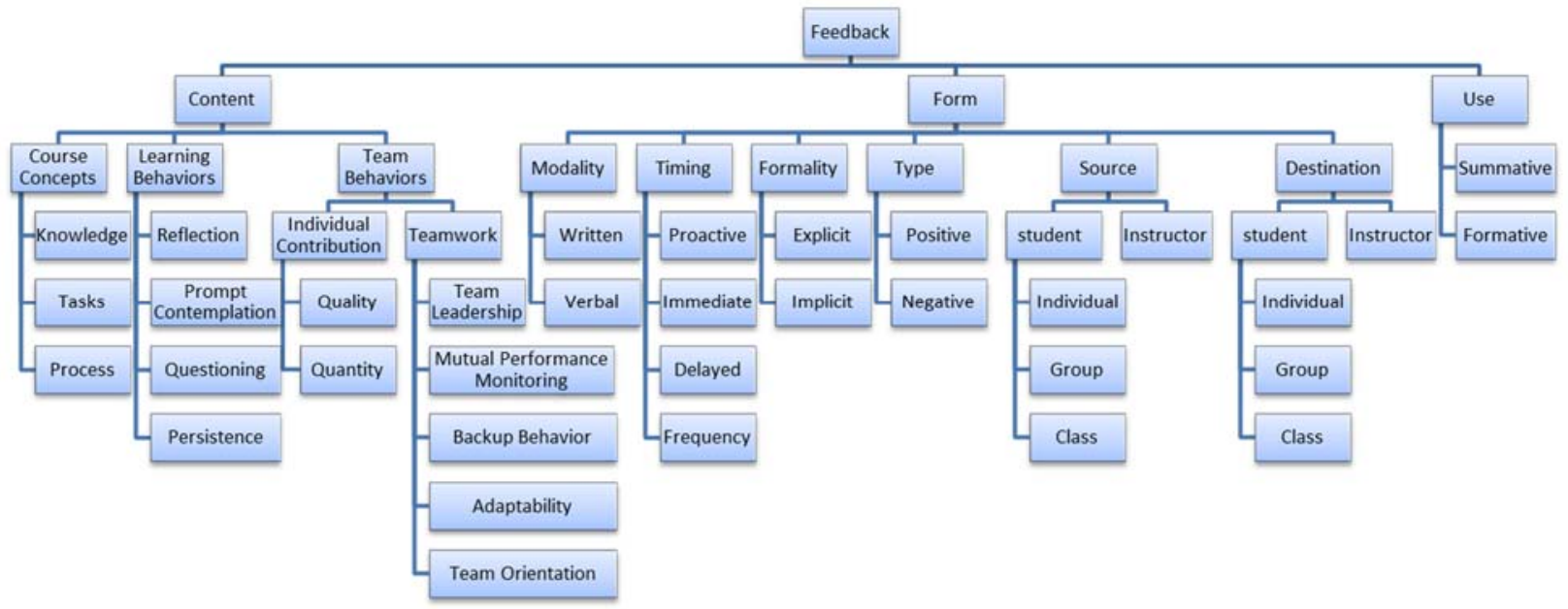

Fig. 1. A taxonomy of instructional feedback. There are three dimensions of feedback: content, form, and use. 


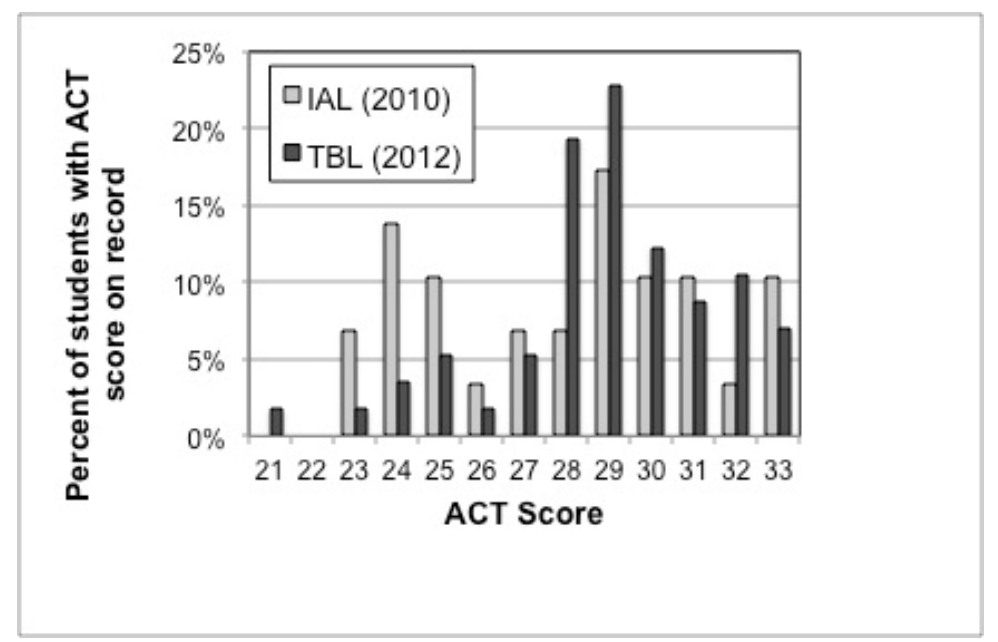

Fig. 2. The distribution of composite ACT scores for students in the IAL and TBL sections. There were 29 (out of $N=44$ ) ACT records for the IAL section and 57 (out of $N=63$ ) ACT records for the TBL section. 


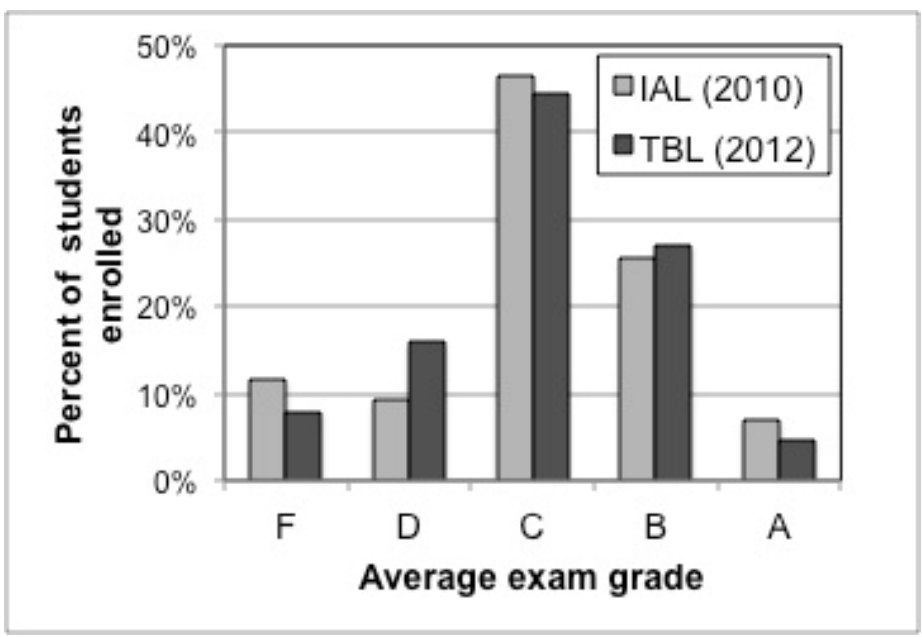

Fig. 3. The distribution of exam grades earned by students in the IAL and TBL sections. 

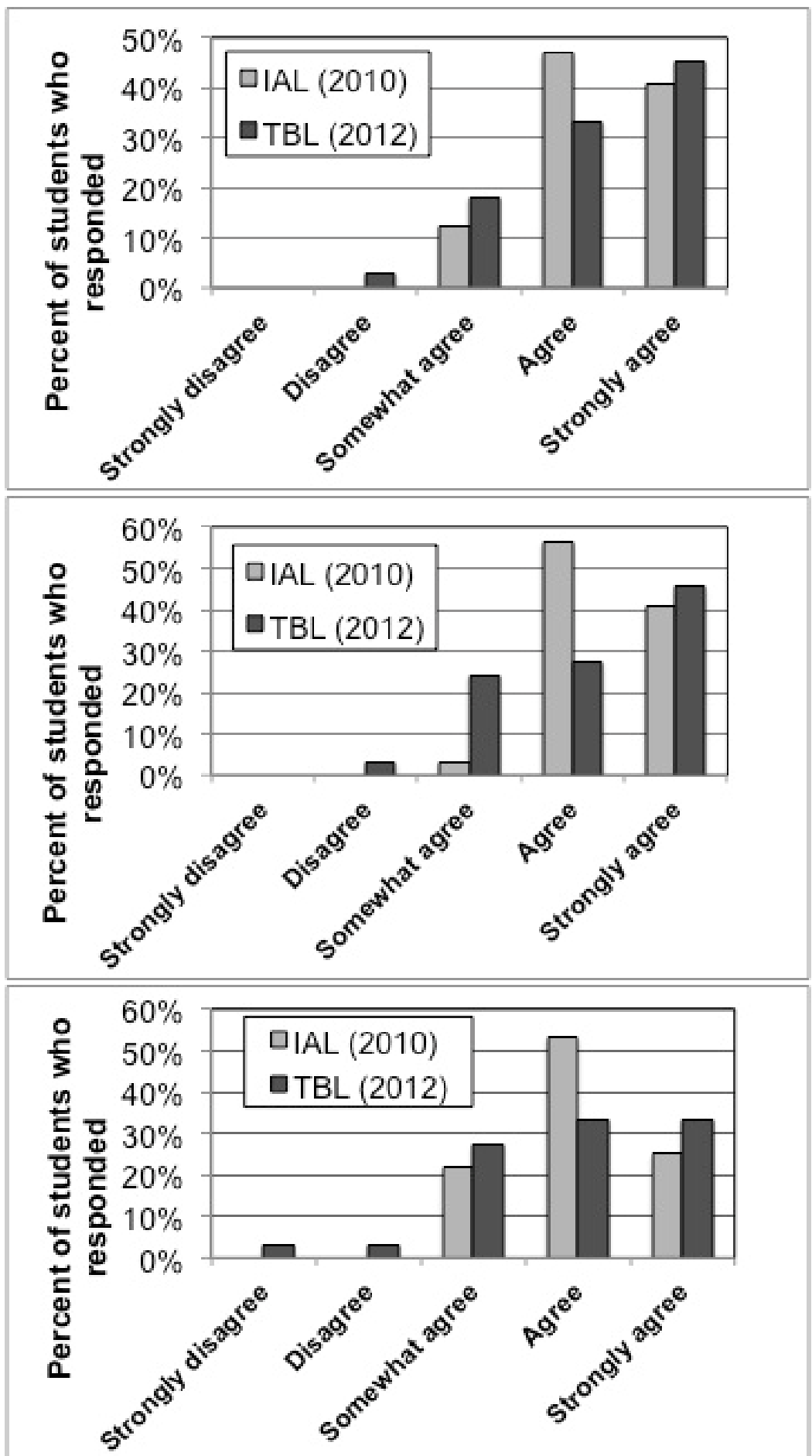

Fig. 4. The distribution of student responses to questions about their perceived attainment of learning outcomes: a) developing and applying material and energy balance equations, b) creating process diagrams for simple and moderately complex chemical systems, c) solving material and energy balance problems using computational tools. 

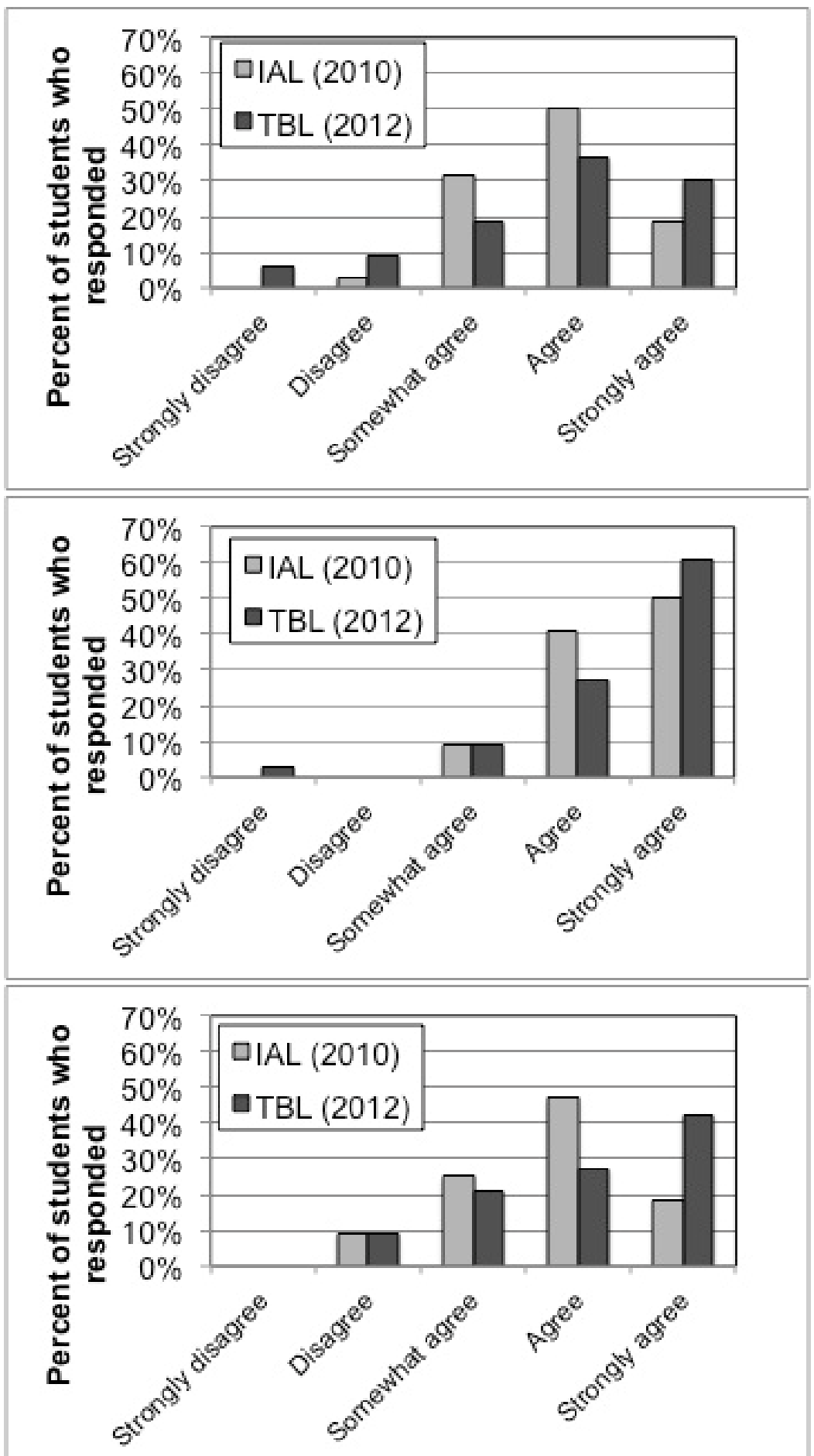

Fig. 5. The distribution of student responses to questions about their professional development: a) developing skills in engineering design, b) working effectively as a member of a team, c) presenting technical information. 